\title{
Original
}

\section{Usefulness of Exercise Induced QT Interval Behavior for Evaluating Viability of Reperfused Infarct-related Myocardium}

\author{
Hui-Ling $\mathrm{LI}^{1}{ }^{1}$, Yasushi AkUtsu' ${ }^{1)}$, Akira ShINOzUKa ${ }^{2)}$, \\ Yusuke Kodama $^{1)}$, Hideyuki Yamanaka ${ }^{1)}$ and Takashi KATAGIRI ${ }^{1)}$
}

\begin{abstract}
We examined the effectiveness of QT interval behavior in evaluating the viability of reperfused infarct-related myocardium in patients with myocardial infarction. Exercise thallium-201 single photon emission computed tomography was performed six months following successful direct angioplasty on 67 patients $(60.6 \pm 11.5$ years $)$ with myocardial infarction. QTc interval and QT dispersion from 12 lead electrocardiography and the number of perfusion defect areas from SPECT images were measured at rest and during exercise. Sixty-two patients with a resting perfusion defect were divided into 3 groups based on the SPECT image patterns. Group A consisted of 11 patients with partial redistribution, Group B consisted of 18 patients with reverse redistribution, and Group $\mathrm{C}$ consisted of 32 patients with fixed defect. The change in the number of defect areas from rest to exercise was related to the change in maximal QTc interval $(y=15.4-3.31 X, r=0.298, p=0.0138)$. The maximal QTc interval was longer in all groups with myocardial infarction compared with 12 normal volunteers at rest $(\mathrm{p}<0.05)$, and increased during exercise in group $B(465.8 \pm 46.6$ to $487.8 \pm 27.2, p=0.0193)$ and group $C$ $(458.7 \pm 25.4$ to $479.5 \pm 31.1, \mathrm{p}<0.0001)$, but not in group $\mathrm{A}(458.9 \pm 26.4$ to $462.1 \pm 25.8, \mathrm{p}=$ not significance). QT dispersion decreased during exercise in the former 2 groups $(62.9 \pm 30.3$ to $42.3 \pm 14.7$, in group $\mathrm{B}, \mathrm{p}=0.0102,53.8$ \pm 20.3 to $41.7 \pm 18.7$, in group $C, p=0.0002)$, but not group $A(45.6 \pm 22.3$ to $32.8 \pm 9$, in the group $\mathrm{A}, \mathrm{p}=$ no significance). QT interval behavior is an effective predictor of scarred myocardial viability following reperfusion.
\end{abstract}

Key words: QT interval, SPECT, exercise testing, reperfusion, myocardial infarction

\section{Introduction}

During the resting state, prolongation of QT interval ${ }^{1-2)}$ or QT dispersion ${ }^{3-4)}$ is associated with prior myocardial infarction or coronary artery disease. Similar result are reported during physical exercise ${ }^{5,6)}$, pacing exercise ${ }^{7)}$ or pharmacological exercise ${ }^{8)}$. Previous studies have demonstrated a relationship between QT interval behavior and the degree of successful thrombolysis in infarct-related myocardium,. The relationship between QT interval behavior

\footnotetext{
1) Third Department of Internal Medicine, Showa University School of Medicine, 1-5-8 Hatanodai, Shinagawa-ku, Tokyo 142-8666, Japan.

${ }^{2)}$ Department of Radiology, Showa University School of Medicine.
} 
and the viability of infarct-related myocardium after reperfusion following acute myocardial infarction has not been clarified. An evaluation of this relationship is useful for practicing physicians, since the viability of reperfused but injured myocardium can influence the prognosis ${ }^{9)}$. We investigated whether the image patterns from exercise perfusion SPECT in the patients with myocardial infarction after early reperfusion are related to QT interval behavior at that time.

\section{Methods}

\section{Study population}

We studied 67 patients ( 51 males and 16 females, mean age; $60.6 \pm 11.5$ years.) who underwent exercise thallium-201 SPECT 6 months after coronary reperfusion with direct angioplasty following a first acute myocardial infarction. Only one diseased vessel, the infarct-related coronary artery, was selected for this study. Patients who had undergone coronary artery bypass surgery or percutaneous transluminal coronary angioplasty were excluded from the study. Also excluded from this study were patients who demonstrated atrial fibrillation, conduction abnormalities, severe left ventricular hypertrophy, severe valvular heart disease, cardiomyopathy, or those who were taking antiarrhythemic drugs. Myocardial infarction was diagnosed from typical chest pain, ST segment elevation, later abnormal Q wave on ECG, and elevated creatine kinase $(4440 \pm 2701$, range 729 to 14380 Unit/L). Coronary artery segments involved in the infarction and the diameter of stenotic areas were classified visually according to the American Heart Association guidelines. When patients underwent cardiac catheterization in the acute phase of myocardial infarction within 6 hours of onset and had the infarct-related coronary artery stenosis of more than $75 \%$, coronary angioplasty was successfully achieved with a Thrombolysis In Myocardial Infarction (TIMI) trial grade III flow ${ }^{10)}$. The infarct-related coronary artery was improved to a residual diameter stenosis of less than $50 \%$. The regional wall motion was measured using a centerline method applied to the left ventriculographic findings. Scored were 0 for akinesis and dyskinesis, 1 for severe hypokinesis, 2 for moderate and mild hypokinesis, and 3 for normal regional motion. Angiographic interpretation was achieved in a blinded. The study was also carried out on 12 healthy volunteers with a mean age of $61.7 \pm 9.6$ years with no past history of ischemic heart disease. Written informed consent was obtained from all patients in this study.

\section{Myocardial perfusion SPECT with exercise}

Exercise was performed on an upright bicycle ergometer, initially at 50 Watts of workload and increased stepwise by 25 Watts every 3 minutes. At the onset of chest pain, significant ECG changes ( $>2 \mathrm{~mm}$ ST-segment depression), or excessive leg fatigue, exercise was terminated. With a 12-lead ECG, heart rate and blood pressure were monitored at one-minute intervals throughout the study. At the peak of exercise, $3 \mathrm{mCi}(111 \mathrm{MBq})$ of thallium-201 was injected intravenously and flushed with normal saline solution. Patients were asked to continue exercising for an additional minute. SPECT images were obtained after 20 minutes of recovery and 4 hours after termination of exercise. The short-axis images of the left ventricle were divided into the apical, middle, and basal slice levels using a polar map, with the latter 2 levels further divided into 8 areas, to yield a total of 17 regions. A myocardial perfusion defect was considered present if the percentage uptake of 


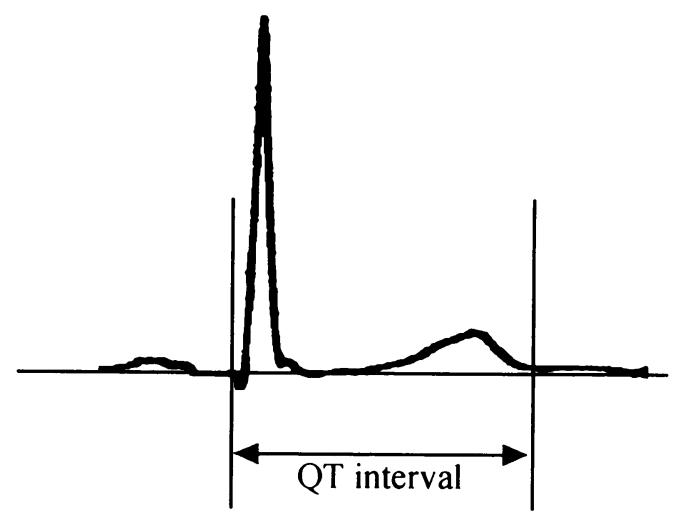

Fig. 1. Measurement of QT interval

radioactive counts in any one of the mapped areas was 2.5 standard deviations below the mean normal limit. The magnitude of each perfusion defect was scored as the number of myocardial areas below this limit. The worsening or improvement of more than one defect area after 4 hours resting was considered evidence of redistribution or reverse redistribution. The worsening or improvement of one or no defect areas, or comparable defect areas, after 4 hours resting was considered evidence of fixed ischemia.

\section{QTc interval and QTc dispersion measurements}

Standard 12 lead ECGs were recorded at a paper speed of $50 \mathrm{~mm} / \mathrm{s}$. QT intervals were measured in a blind fashion from ECGs that were magnified 200\%. A mean value was calculated for 3 consecutive QT intervals. QT intervals were measured from the start of the inscription of the QRS complex to the point at which the $T$ wave returned to the isoelectric line (Fig. 1). If a $U$ wave was present, the termination of the $T$ wave was defined as the nadir between the $T$ and $U$ waves. A minimum of 9 ECG leads was analyzed. The QT intervals were corrected for heart rate $(\mathrm{QTc})$ using Bazett's formula ${ }^{11)}$. The maximum and minimum QTc intervals were measured from any one of the 12 leads. QT dispersion was defined as the difference between the maximal and minimal QT intervals. Only uncorrected values of QT intervals were used for the assessment of QT dispersion ${ }^{12}$.

Study group: Based on results from exercise SPECT at 6 months after reperfusion following myocardial infarction, 62 patients with resting perfusion defects were divided into 3 groups (Fig. 2). Group A consisted of 11 patients where the presence of partial redistribution was represented as the infarct-related myocardium with scar and ischemia. Group B consisted of 18 patients where the presence of reverse redistribution was represented as the infarct-related myocardium with scar and injury. Group C consisted of 33 patients where the fixed perfusion defect was represented as the infarct-related myocardium with scar. Five patients with no perfusion defect at rest were excluded from this study, because the completely recovered infarct-related myocardium could not be used in the evaluation of myocardial damage following myocardial infarction.

\section{Statistical analysis}

Comparisons between groups were performed using one-way analysis of variance 


\section{Group A :}

Scar and Ischemia

(Partial redistribution)

\section{Group B :}

Scar and Injury

(Reverse redistribution)

\section{Group C :}

\section{Scar}

(Fixed perfusion defect)

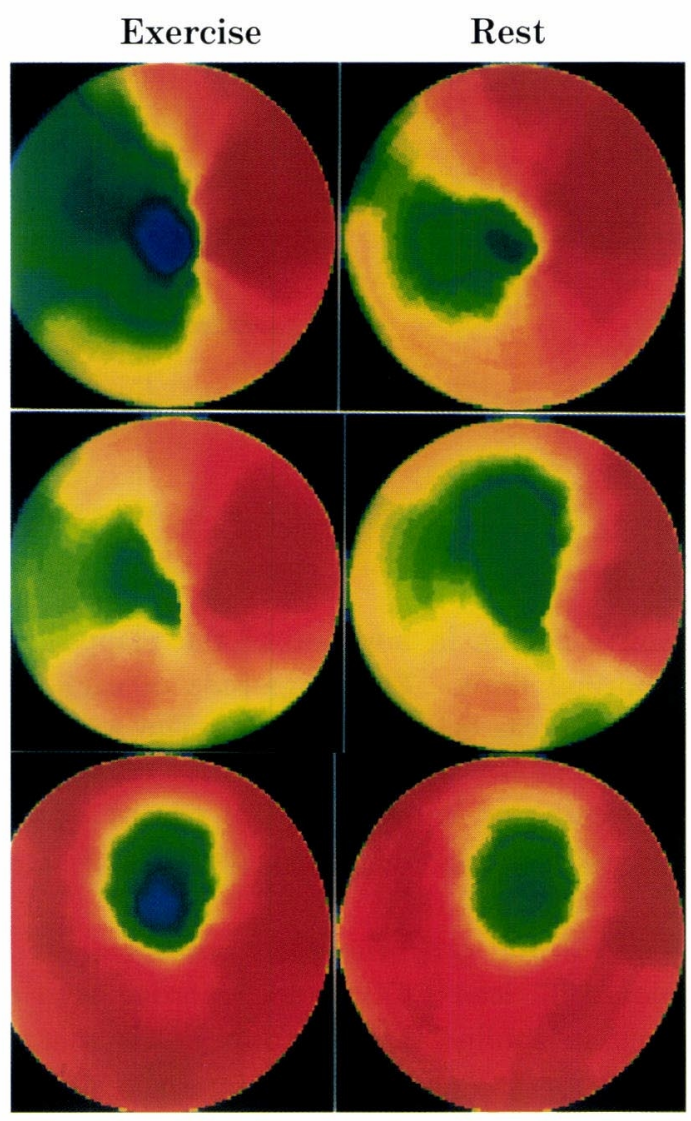

Fig. 2. Polar map structured by short-axis SPECT images. The patients were divided into 3 groups based on the SPECT image patterns.

Group A : the presence of partial redistribution was represented as the infarct-related myocardium with scar and ischemia in 11 patients. Group B: the presence of reverse redistribution was represented as the infarct-related myocardium with scar and injury in 18 patients. Group C: the fixed perfusion defect was represented as the infarct-related myocardium with scar in 33 patients.

(ANOVA) for continuous variables and the chi-square test for categorical variables. Comparisons between rest and exercise were performed using the paired t-test. A p value of less than 0.05 was considered statistically significant. All data was presented as mean \pm 1 standard deviation.

\section{Results}

\section{Exercise SPECT results}

There was no significant difference in the number of resting defect areas between groups in this study (Table 1). Group A exhibited the greatest number of defect areas at peak exercise, and the greatest change in the number of defect areas as a response to exercise $(\mathrm{p}=0.0249$ and $\mathrm{p}<0.0001)$. There was no significant difference in maximal creatine kinase after myocardial infarction between the three groups $(4375 \pm 2136$ in group A, $3832 \pm 2049$ in group B, $5171 \pm 4206$ in group C). 
Table 1. Exercise SPECT results in patients with reperfused myocardial infarction

\begin{tabular}{lcccc}
\hline & \multicolumn{4}{c}{ Patients with myocardial infarction $(\mathrm{n}=62)$} \\
& $\begin{array}{c}\text { Group A } \\
\text { Scar and Ischemia } \\
(\mathrm{n}=11)\end{array}$ & $\begin{array}{c}\text { Group B } \\
\text { Scar and Injury } \\
(\mathrm{n}=18)\end{array}$ & $\begin{array}{c}\text { Group C } \\
\text { Scar } \\
(\mathrm{n}=33)\end{array}$ & $\begin{array}{c}\text { P value } \\
\text { (ANOVA) }\end{array}$ \\
\hline Number of defect areas at rest & $4.8 \pm 2.9$ & $7.6 \pm 4.7$ & $5.2 \pm 3.2 \dagger$ & $\mathrm{p}=\mathrm{N} . \mathrm{S}$. \\
Number of defect areas at peak exercise & $8.1 \pm 3.1$ & $4.6 \pm 4.3^{*}$ & $4.8 \pm 3.3^{*}$ & $\mathrm{p}=0.0249$ \\
Change in number of defect areas & $+3.3 \pm 2.1$ & $-2.9 \pm 2.6^{* * * *+\dagger \dagger \dagger}$ & $-0.4 \pm 0.7^{* * * *}$ & $\mathrm{p}<0.0001$ \\
\hline
\end{tabular}

${ }^{*} \mathrm{p}<0.05,{ }^{* *} \mathrm{p}<0.01,{ }^{* * *} \mathrm{p}<0.001$ versus the group with scar and ischemia. All data were expressed as the mean \pm 1 standard deviation

Table 2. Cardiac catheterization findings in patients with reperfused myocardial infarction

\begin{tabular}{|c|c|c|c|c|}
\hline & \multicolumn{4}{|c|}{ Patients with reperfused myocardial infarction $(n=63)$} \\
\hline & $\begin{array}{c}\text { Group A } \\
\text { Scar and Ischemia } \\
(\mathbf{n}=11)\end{array}$ & $\begin{array}{c}\text { Group B } \\
\text { Scar and Injury } \\
(n=18)\end{array}$ & $\begin{array}{l}\text { Group C } \\
\text { Scar } \\
(n=33)\end{array}$ & $\begin{array}{c}\text { P value } \\
(\text { ANOVA })\end{array}$ \\
\hline \multicolumn{5}{|l|}{ Infarct-related coronary artery } \\
\hline LAD involved & $8(72.7 \%)$ & $14(77.8 \%)$ & $19(57.6 \%)$ & \\
\hline RCA involved & $2(18.2 \%)$ & $3(16.7 \%)$ & $9(27.3 \%)$ & \\
\hline LCX involved & $1(9.1 \%)$ & $1(5.5 \%)$ & $5(15.2 \%)$ & $\mathrm{p}=\mathbf{N} . \mathbf{S}$. \\
\hline Restenosis at 6 months after reperfusion & $6(54.5 \%)$ & $7(38.9 \%)$ & $10(30.3 \%)$ & $\mathrm{p}=$ N.S. \\
\hline \multicolumn{5}{|l|}{ Before reperfusion } \\
\hline Regional wall motion score & $0.6 \pm 0.8$ & $0.5 \pm 0.8$ & $0.5 \pm 0.7$ & $\mathrm{p}=\mathbf{N} . \mathbf{S}$. \\
\hline LVEF (\%) & $45.6 \pm 9.2$ & $45.8 \pm 11.2$ & $48 \pm 9.9$ & $\mathrm{p}=\mathbf{N} . \mathbf{S}$. \\
\hline \multicolumn{5}{|l|}{ After reperfusion } \\
\hline Regional wall motion score & $0.6 \pm 0.7$ & $1.3 \pm 1.1^{*}$ & $1.3 \pm 1.1^{* *}$ & $\mathrm{p}=\mathbf{N} . \mathbf{S}$. \\
\hline LVEF (\%) & $49.9 \pm 7.9$ & $56.5 \pm 12.7^{* *}$ & $52.7 \pm 10.2^{*}$ & $\mathrm{p}=\mathbf{N} . \mathrm{S}$. \\
\hline
\end{tabular}

$\mathrm{LAD}=$ left anterior descending artery, $\mathrm{RCA}=$ right coronary artery, $\mathrm{LCX}=$ left circumflex artery. $\mathrm{LVEF}=$ left ventricular ejection fraction, ${ }^{*} \mathrm{p}<0.05,{ }^{* *} \mathrm{p}<0.01$ versus the parameters before reperfusion. All data were expressed as the mean \pm 1 standard deviation

\section{Cardiac catheterization findings before reperfusion and 6 months after reperfusion}

Of the 62 patients with myocardial infarction, the infarct-related coronary artery was the left anterior descending artery in 41 patients, the right coronary artery in 14, and the left circumflex artery in 7. At 6 months after reperfusion, a restenosis of reperfused infarct-related coronary artery presented more often in the group with scar and ischemia compared to other infarct-related groups (54.5\% versus $38.9 \%$ and $30.3 \%)$.

At the acute phase of myocardial infarction before reperfusion, there was no significant difference between groups for the infarct-related wall motion score and the left ventricular ejection fraction (LVEF). At the chronic phase 6 month after reperfusion, regional wall motion and LVEF improved significantly $(\mathrm{p}<0.05)$ in the group $\mathrm{B}$ and $\mathrm{C}$, while in group A, improvement was not evident (Table 2). 
Table 3. Exercise-induced ECG change in patients with reperfused myocardial infarction

\begin{tabular}{|c|c|c|c|c|}
\hline & \multicolumn{4}{|c|}{ Patients with myocardial infarction $(n=62)$} \\
\hline & $\begin{array}{c}\text { Group A } \\
\text { Scar and Ischemia } \\
(\mathbf{n}=11)\end{array}$ & $\begin{array}{c}\text { Group B } \\
\text { Scar and Injury } \\
(n=18)\end{array}$ & $\begin{array}{c}\text { Group C } \\
\text { Scar } \\
(n=33)\end{array}$ & $\begin{array}{c}\text { P value } \\
\text { (ANOVA) }\end{array}$ \\
\hline \multicolumn{5}{|l|}{ Peak exercise } \\
\hline The presence of ischemic ST depressions & $2(18.2 \%)$ & $0(0 \%)$ & $3(9.1 \%)$ & $\mathrm{p}=\mathbf{N} . \mathbf{S}$. \\
\hline The presence of ST elevations & $4(36.4 \%)$ & $8(44.4 \%)$ & $7(21.2 \%)$ & $\mathrm{p}=\mathbf{N} . \mathbf{S}$. \\
\hline
\end{tabular}

All data were expressed as the mean \pm 1 standard deviation

Table 4. Hemodynamic results in patients with reperfused myocardial infarction

\begin{tabular}{|c|c|c|c|c|c|}
\hline & \multicolumn{5}{|c|}{ Patients with myocardial infarction $(n=62)$} \\
\hline & $\begin{array}{c}\text { Group A } \\
\text { Scar and Ischemia } \\
(n=11)\end{array}$ & $\begin{array}{c}\text { Group B } \\
\text { Scar and Injury } \\
(\mathbf{n}=18)\end{array}$ & $\begin{array}{l}\text { Group C } \\
\text { Scar } \\
(n=33)\end{array}$ & $\begin{array}{c}\text { Normal } \\
\text { volunteers } \\
(\mathrm{n}=12)\end{array}$ & $\begin{array}{c}\text { P value } \\
\text { (ANOVA) }\end{array}$ \\
\hline Exercise duration (minutes) & $7.0 \pm 1.7$ & $10.2 \pm 2.8^{* *}$ & $9.7 \pm 3.1^{* *}$ & $10.1 \pm 2.5^{* *}$ & $\mathrm{p}=0.0166$ \\
\hline HR (beat/minute) at peak exercise & $142 \pm 19$ & $143 \pm 21$ & $138 \pm 16$ & $143 \pm 21$ & $\mathrm{p}=\mathbf{N} . \mathbf{S}$. \\
\hline SBP $(\mathrm{mmHg})$ at peak exercise & $206 \pm 44$ & $193 \pm 30 \dagger \dagger$ & $192 \pm 32 \dagger \dagger$ & $228 \pm 32$ & $\mathrm{p}=\mathbf{N} . \mathbf{S}$. \\
\hline DBP $(\mathrm{mmHg})$ at peak exercise & $94 \pm 16$ & $100 \pm 28$ & $97 \pm 15$ & $101 \pm 17$ & $\mathrm{p}=\mathbf{N} . \mathbf{S}$. \\
\hline RPP at peak exercise (beats ${ }^{*} \mathrm{mmHg}$ ) & $29163 \pm 6588$ & $27813 \pm 6715 \dagger 2$ & $26433 \pm 5269 \dagger \dagger$ & $33106 \pm 8546$ & $\mathrm{p}=0.0264$ \\
\hline
\end{tabular}

\section{Hemodynamic and ECG change with exercise}

Of the 62 patients with reperfused myocardial infarction, 3 patients $(4.8 \%)$ had typical chest pain during exercise. Five patients $(8.1 \%)$ had exercise-induced ischemic ST-segment depressions of $0.1 \mathrm{mV}$ on ECG, and $19(30.4 \%)$ had exercise-induced ischemic ST-segment elevation of $0.1 \mathrm{mV}$. There were no significant differences in these measurements between the three groups (Table 3 ).

Table 4 shows various hemodynamic parameters monitored throughout the exercise testing. At peak exercise, the rate-pressure product was higher in normal volunteers than any group with reperfused myocardial infarction, but was comparable among the three groups with myocardial infarction.

\section{QTc interval at rest and exercise}

Fig. 3 shows the correlation between the change in QTc interval behavior from rest to exercise and the number of defect areas. The number of defect areas was related to a change in the maximal QTc interval $(y=15.4-3.31 X, r=0.298, p=0.0138)$, but not the minimal QTc interval.

There was no significant difference in the minimal QTc interval between rest and exercise for patients with myocardial infarction or for normal volunteers (Fig. 4). Compared with the control level determined for normal volunteers, the minimal QTc interval was 


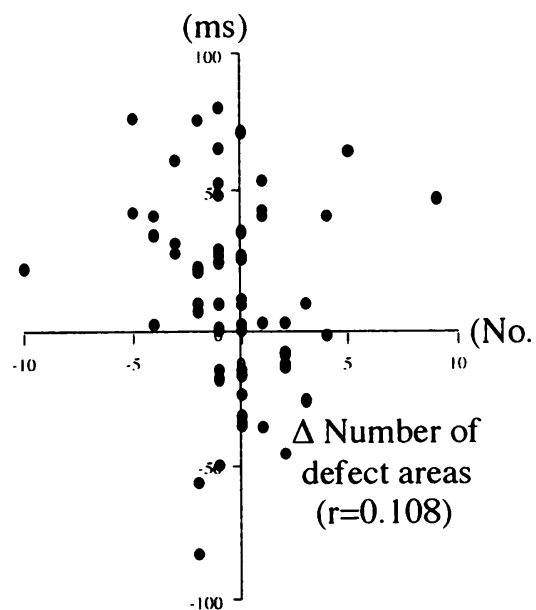

$\Delta$ minimum QTc interval $(\mathrm{mm})$

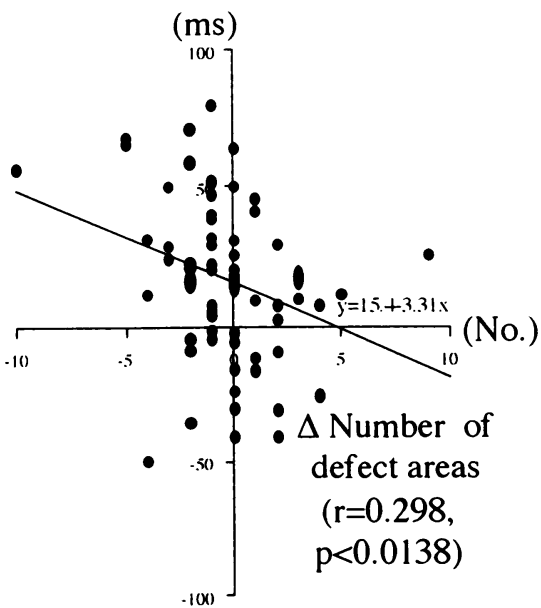

$\Delta$ maximum QTc interval $(\mathrm{mm})$

Fig. 3. Effect of exercise on minimal or maximal QTc interval behavior measured by ECG leads (minimal and maximal QTc interval), and the number of perfusion defect areas measured by thallium-201 SPECT.

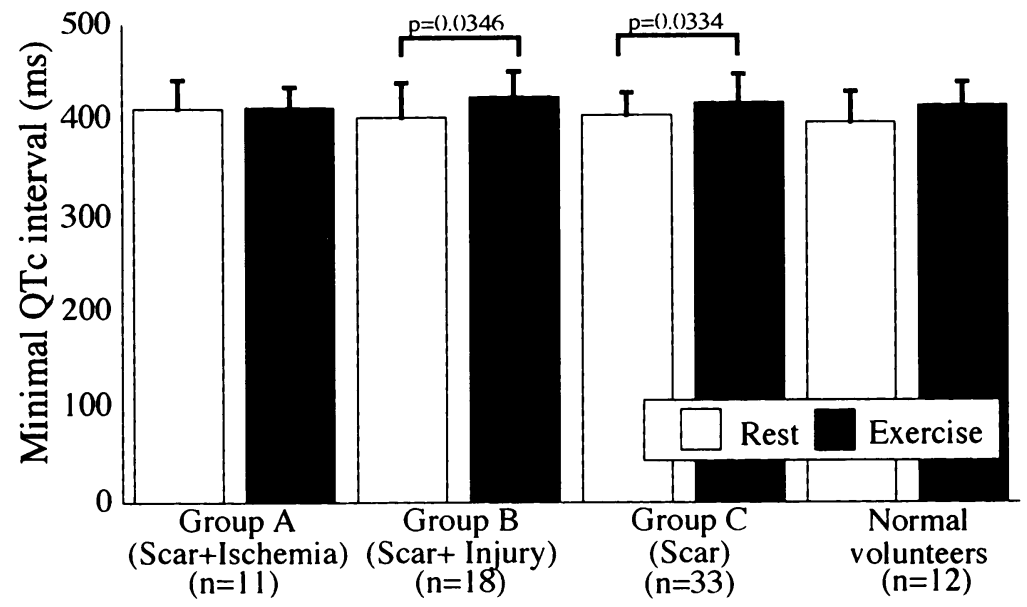

Fig. 4. Minimal QTc interval behavior $($ mean \pm SD) at rest and at peak exercise. The study groups consist of group A, 11 patients with scarred and ischemic infarct-related myocardium, group B, 18 patients with scarred and injured infarct-related myocardium, group C, 33 patients with only scarred myocardium, and the group with 12 normal volunteers..

unchanged in group A but was elevated in group $B$ and $C(p=0.0346$ and $p=0.0334$, respectively).

The resting maximal QTc interval was longer in all patients with myocardial infarction compared to the normal volunteers. Among the groups with myocardial infarction the maximal QTc interval at rest was comparable. At peak exercise, the maximal QTc interval 


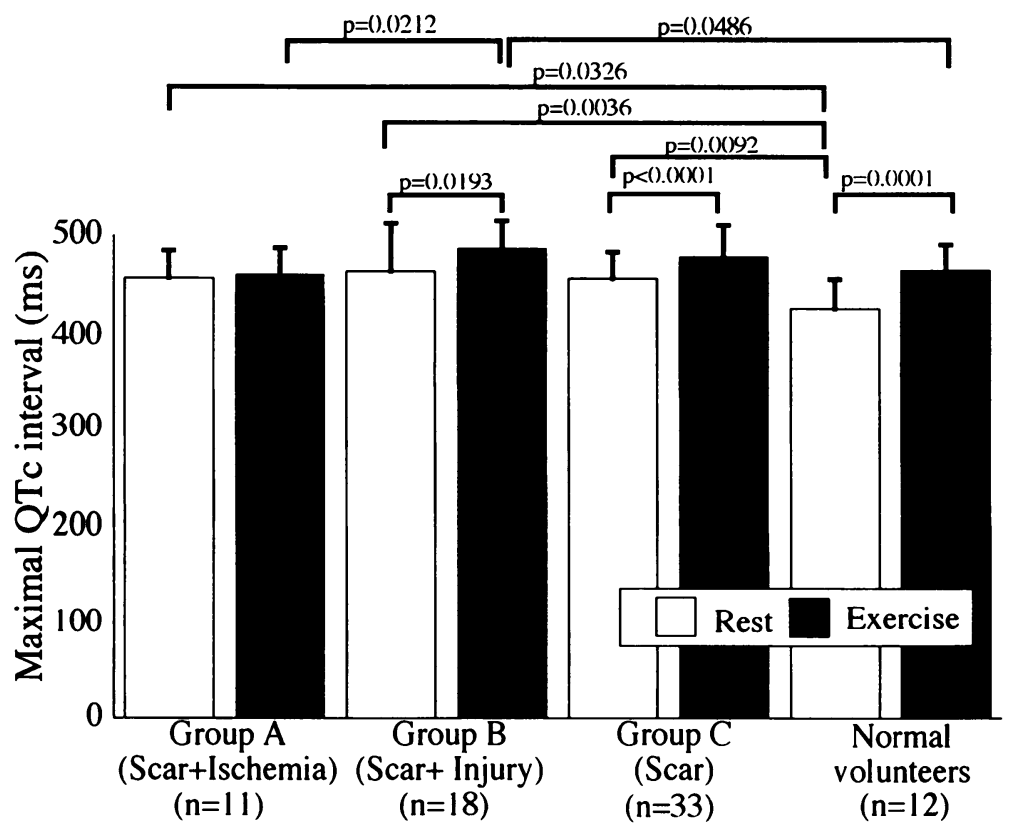

Fig. 5. Maximal QTc interval behavior $($ mean \pm SD) at rest and at peak exercise. The study groups consist of group A, 11 patients with scarred and ischemic infarct-related myocardium, group B, 18 patients with scarred and injured infarct-related myocardium, group C, 33 patients with only scarred myocardium, and the group with 12 normal volunteers.

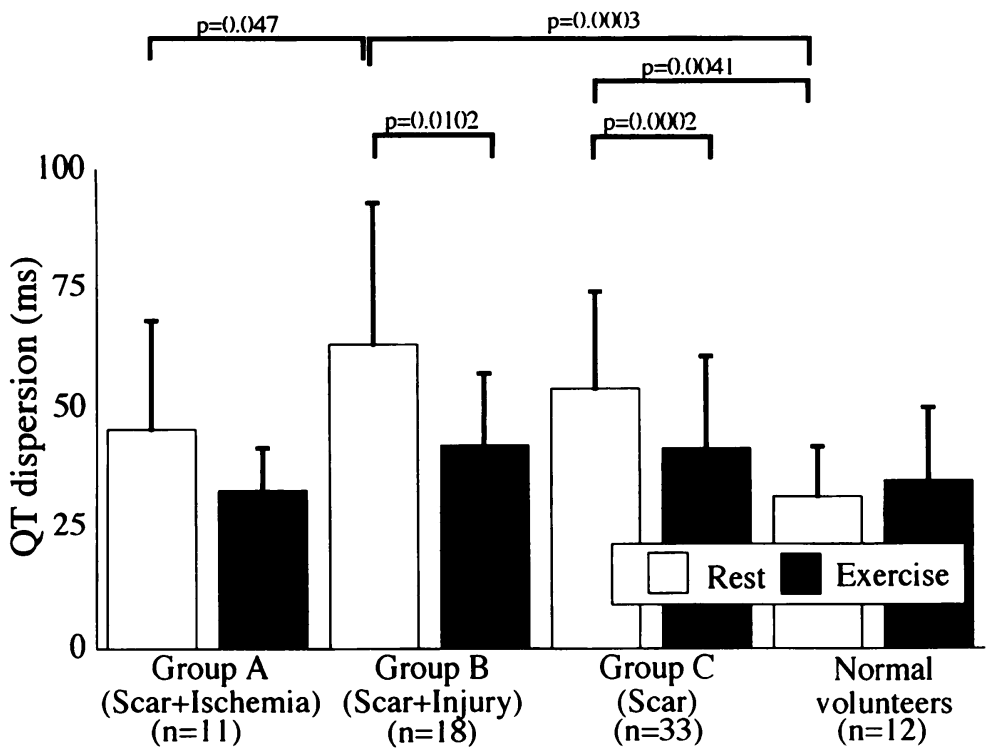

Fig. 6. QT dispersion (mean $\pm \mathrm{SD}$ ) at rest and at peak exercise. The study groups consist of group A, 11 patients with scarred and ischemic infarct-related myocardium, group B, 18 patients with scarred and injured infarct-related myocardium, group C, 33 patients with only scarred infarct-related myocardium, and the group with 12 normal volunteers. 
was elevated in group $B$, group $C$ and normal volunteers $(p=0.0193, p<0.0001$, and $\mathrm{p}=0.0001$, respectively), but not in group A (Fig. 5)

\section{$Q T$ dispersion at rest and exercise}

Fig. 6 shows a longer resting QT dispersion for group $\mathrm{B}$ and $\mathrm{C}$ than for the normal volunteers $(p=0.0003$ and $p=0.0041)$. This value was comparable between group $A$ and the normal volunteers. Resting QT dispersion decreased significantly during exercise for group $B$ and $C(p=0.0102$ and $p=0.0002)$, but not for group $A$ or the normal volunteers. QT dispersion decreased in more than 3 quarters of patients in group $B$ and $C$, and increased in half of the patients in group $\mathrm{A}$ and the group of normal volunteers $(45.5 \%$ of 5 patients in group A, $77.8 \%$ in 14 of 18 patients in group B, $72.7 \%$ in 24 of 33 in group $\mathrm{C}$, and $50 \%$ in 6 of 12 in normal volunteers, respectively).

\section{Discussion}

The close relationship between QT interval behavior or QT dispersion and myocardial ischemia was demonstrated using physical exercise. Yi et al demonstrated that there was a significant difference in QT interval behavior or QT dispersion at peak exercise between post-infarction patients and normal subjects ${ }^{13)}$. Furthermore, the maximal QTc interval at peak exercise was longer in patients that died suddenly (maximum QTc interval $>440 \mathrm{~ms}$ ) compared with survivors. In agreement with these results, Lowe et al demonstrated that an exercise-induced change in QT dispersion (or QT interval behavior) in patients with triple vessel disease was greater than in patients with disease in one or two vessels (change in QT dispersion $>16 \mathrm{~ms}$, exercise-induced QT dispersion $>60 \mathrm{~ms})^{6)}$. The present study is the first to identify a relationship between QT interval behavior and the degree (severity or viability) of the myocardial damage in the chronic phase of infarct-related myocardium with reperfusion. We report that the change in the perfusion defect score with exercise is closely related to the change in maximal QTc interval.

The aim of infarct-related coronary artery reperfusion therapy in acute myocardial infarction is to preserve left ventricular function by achieving complete myocardial salvage. A problem with this therapy is the presence of $Q$ waves on infarct-related ECG leads in the chronic phase after early reperfusion of the occluded coronary artery and the development of myocardial scar, detected by stress perfusion SPECT, on salvaged infarct-related myocardium. Scintigraphic image patterns in viable but infarct-related myocardium after reperfusion are related to myocardial injury, degree, risk and myocardial function ${ }^{9,14-16)}$.

The global left ventricular ejection fraction and infarct-related regional wall motion did not improve by 6 months after reperfusion in the scar and ischemia group. The resting perfusion defect score at 6 months after reperfusion and the creatine kinase level during the acute phase of myocardial infarction, which represents infarct size, were comparable among all groups in this study. The reperfused infarct-related myocardium showing fixed perfusion defect on exercise SPECT images in the scar group showed the lowest level of myocardial damage. This is because the myocardium recovered completely allowing normal myocardial perfusion flow at rest and during exercise. A previous study ${ }^{16)}$ reported that the infarctrelated myocardium of scar and injury patients, that showed reverse redistribution on stress SPECT imaging, had a lower level of damage compared with those with partial redistribution. Therefore, it is important to evaluate the severity of myocardial damage based on the 
scintigraphic image patterns for the patients with reperfused $Q$ wave myocardial infarction. QT interval behavior on the surface electrocardiogram reflects ventricular repolarization, while QT dispersion reflects its heterogeneity. Our results show that myocardial damage of viable myocardium with scar after reperfusion leads to the change in ventricular repolarization.

In the present study, patients with the scarred and ischemic myocardium did not display an increase in the maximal QTc interval, or a decrease in QT dispersion during exercise. In contrast, patients with scarred myocardium and no ischemia did show an increase in QT interval and a decrease in QT dispersion during exercise. Schneider, et al reported that the larger the average FDG uptake in the infarct-related myocardium, the greater the decrease in QT dispersion (or maximal QT interval) ${ }^{17}$. . Thus, the greater the severity of myocardial damage in viable but infarct-related myocardium, the greater the change in QT interval behavior. In the presence of myocardial scar, QT interval behavior increases during exercise. This result is consistent with previous studies ${ }^{13)}$ and explains our observations for the scar and ischemia group. In the scar and ischemia group an increase in the QT interval caused by the myocardial scar and a decrease in the QT interval caused by the severity of myocardial damage may have occurred simultaneously during exercise and lead to no changes being recorded for QT interval and QT dispersion during exercise.

Teragawa et al identified patients with scarred and ischemic myocardium from a scar group using QT dispersion and the change in QT dispersion under adenosine triphosphate ${ }^{8)}$. Unlike the present study, they did not provide the homogeneity of infarct size, the degree of stenosis diameter of the infarct-related coronary artery, the time course from onset of myocardial infarction, and the number of stenotic coronary arteries including the infarct-related coronary artery. QT dispersion and QT interval behavior depends on reperfusion status (the perfusion grade of TIMI) ${ }^{18)}$, time course after onset ${ }^{1)}$ and infarct size $^{17)}$ in patients with acute myocardial infarction. During physical and pacing exercise, QT dispersion and QT interval behavior Is closely related to the number of vessel disease ${ }^{6)}$ and the severity of ischemia as measured by the cardiac lactate extraction rate ${ }^{7,19}$.

In the present study, the differences in image patterns with myocardial scar on exercise SPECT were compared for homogeneity of infarct size, one vessel disease, first myocardial infarction, and follow-up assessment of 6 months after reperfusion following onset of myocardial infarction. Combining this information with QTc interval behavior and QT dispersion during physical exercise we could distinguish the scar and ischemia group from the scar group as a whole or from the scar and injury group.

Identification of the scar and ischemia group is important for predicting the prognosis of patients with reperfused myocardial infarction ${ }^{9)}$. Disadvantages of this identification process are that nuclear medicine is time consuming and expensive and is usually only available at specialized medical centers. A simple and inexpensive method allowing estimation of the condition of infarct-related myocardium after reperfusion would be advantageous.

In the present study, restenosis of the reperfused infarct-related coronary artery was most common in the group with scar and ischemia compared to other infarct-related groups. Exercise SPECT imaging was not always sensitive enough to indicate restenosis in this group. Previous studies reported that the sensitivity and specificity for detecting restenosis of infarct-related coronary artery was $24 \%$ and $88 \%$ of ST segment deviation using exercise $\mathrm{ECG}^{20)}$, and $64 \%$ and $72 \%$ of reversible ischemia using exercise scintigraphy ${ }^{21)}$. The 
discrepancy between angiography and scintigraphy was thought to be related to local trauma or sustained damage in viable myocardial cell uptake, despite the lack of coronary artery restenosis $^{22)}$.

\section{Study limitations}

Although the small number of patients included in this is a limitation, the consistency of our observation provides a sound basis for future direction and research. Another limitation is the possibility the localization of myocardial ischemia will affect QT dispersion. We believe that this is not significant because the localization in myocardial infarction changes the specific ECG lead ${ }^{23)}$, and the maximal QTc interval behavior reflects the ventricular repolarization in infarct-related myocardium with no relation to the location of the infarct. Lastly, the recording of each 12 ECG lead was neither simultaneous, nor digital. In addition, measurement of the QT interval is sometimes difficult because the terminal portion of the $\mathrm{T}$ wave cannot always be reliably determined.

\section{Conclusions}

In the chronic phase after reperfusion following acute myocardial infarction, the exercise-induced image patterns with myocardial scar on exercise SPECT was closely related to the change in QT interval behavior with exercise. QT interval behavior may be a predictor of the severity of myocardial damage in viable myocardium with scar in reperfused infarct-related myocardium.

\section{Acknowledgements}

We thank Masashi Akiyama, for technical assistance throughout this study. We express our gratitude to Hideki Nishimura, M.D., Tien-Yin Huang, M.D., Hiroki Takenaka. M.D., Hirotsugu Munechika M.D. for their invaluable contributions.

\section{References}

1) Cinca J, Figueras J, Tenorio L, Valle V, Trenchs J, Segura R and Rius J : Time course and rate dependence of Q-T interval changes during noncomplicated acute transluminal myocardial infarction in human beings. $\mathrm{Am}$ J Cardiol 48 : 1023-1028 (1981)

2) Schwartz PJ and Wolf MD: QT interval prolongation as predictor of sudden death in patients with myocardial infarction. Circulation $57: 1074-1077$ (1978)

3) Van de Loo A, Arendts W and Hohnloser SH: Variability of QT dispersion measurements in the surface electrocardiogram in patients with acute myocardial infarction and in normal subjects. Am J Cardiol 74:11131118 (1994)

4) Yunus A, Gillis AM, Traboulsi M, Duff HJ, Wyse DG, Knudtson ML and Mitchell LB : Effect of coronary angioplasty on precordial QT disoersion. Am J Cardiol 79 : 1339-1342 (1997)

5) Romano M, Maro TD, Carella G, Cotecchia MR, Ferro G and Chiariello M : Relation between heart rate and QT interval in exercise-induced myocardial ischemia. Am J Cardiol $56: 861-862$ (1985)

6) Lowe MD, Rowland E and Grace AA : QT dispersion and triple-vessel coronary disease. Lancet 349:11751177 (1997)

7) Sporton SC, Taggart P and Sutton PM : Acute ischemia: a dynamic influence on QT dispersion. Lancet 349 : 306-309 (1997)

8) Teragawa H, Hirao H, Muraoka Y, Yamagata T, Matsuura H and Kajiyama G: Relation between QT dispersion and adenosine triphosphate stress thallium-201 single-photon emission computed tomographic imaging for detecting myocardial ischemia and scar. Am J Cardiol 83:1152-1156 (1999)

9) Kaminek M, Myslivecek M, Husak V, Koranda $\mathbf{P}$ and Lang $\mathbf{O}$ : Prognostic value of myocardial perfusion tomographic imaging in patients after percutaneous transluminal coronary angioplasty. Clin Nucl Med 25 : 
775-778 (2000)

10) The TIMI study group: The thrombolysis in myocardial infarction (TIMI) trial. N Engl J Med 312:932-936 (1985)

11) Bazett HC: An analysis of the time-relations of electrocardiograms. Heart $7: 353-370$ (1920)

12) Malik M and Camm AJ : Mystery of QTc interval dispersion. Am J Cardiol 79: 785-787 (1997)

13) Yi G, Crook R, Guo X, Staunton A, Camm J and Marik $M$ : Exercise-induced changes in the QT interval duration and dispersion in patients with sudden cardiac death after myocardial infarction. Int $J$ Cardiol 63 : 271-279 (1998)

14) Roelants VA, Vanoverschelde JJ, Borght TMV and Melin JA : Reverse redistribution on exercise-redistribution 201Tl SPECT in chronic ischemic dysfunction: Predictive of functional outcome after revascularization?. $J$ Nucl Med $43: 621-627$ (2002)

15) Sridhara BS, Dudzic E, Basu S, Senior R and Lahiri A : Reverse redistribution of thallium-201 represents a low-risk finding in thrombolysed patients following myocardial infarction. Eur J Nucl Med 21: 1094-1097 (1994)

16) Beygui F, Feuvre CL, Maunoury C, Helft G and Metzger JP: Coronary vasodilator reserve: Aclue to the explanation of tl-201 redistribution atterns early after successful primary stenting for acute myocardial infarction. J Am Coll Cardiol $40: 877-881$ (2002)

17) Schneider CA, Voth E, Baer FM, Horst M, Wagner $R$ and Sechtem U: QT dispersion is determined by the extent of viable myocardium in patients with chronic Q-wave myocardial infarction. Circulation 96 : 3913-3920 (1997)

18) Moreno FL, Villanueva T, Karagounis LA and Anderson JL: Reduction in QT interval dispersion by successful thrombolytic therapy in acute myocardial infarction. Circulation 90:94-100 (1994)

19) Stierle U, Giannitsis E, Sheikhzadeh A, Kruger D, Schmucker G, Mitusch R and Potratz J : Relation between QT dispersion and the extent of myocardial ischemia in patients with three-vessel coronary artery disease. Am J Cardiol 81 : 564-568 (1998)

20) Honan MB, Bengtson JR, Pryor DB, Rendall DS, Stack RS, Hinohara T, Skelton TN, Califf RM, Hlatky MA and Mark DB : Exercise treadmill testing is a poor predictor of anatomic restenosis after angioplasty for acute myocardial infarction. Circulation 80 : 1585-1594 (1989)

21) Kosa I, Blasini R, Schneider-Eicke J, Neumann FJ, Matsunari I, Neverve J, Schomig A and Schwaiger M: Myocardial perfusion scintigraphy to evaluate patients after coronary stent implication. J Nucl Med 39:13071311 (1998)

22) Powelson SW, DePuey EG, Roubin GS, Berger HJ and King SB : Discordance of coronary angiography and thallium tomography early after transluminal coronary angioplasty. J Nucl Med 27:900, No99 (abstract) (1986)

23) Cowan JC, Yusoff K, Moore M, Amos PA, Gold AE, Bourke JP, Tansuphaswadikul S and Campbell RW : Importance of lead selection in QT interval measurement. Am J Cardiol 61 : 83-87 (1988) 